\title{
The Septum Magnet System of the New Fast Extraction Channel of the SPS at CERN
}

\author{
W. Weterings, B. Balhan, B. Goddard, and A. Rizzo
}

\begin{abstract}
In the Long Straight Section LSS4 of the Super Proton Synchrotron (SPS) at CERN, a new fast extraction system has been installed in order to extract the beam to ring 2 of the Large Hadron Collider (LHC) and the CERN Neutrino to Gran Sasso facility (CNGS). The system consists of horizontal closed orbit bumper magnets, extraction kicker magnets, enlarged aperture quadrupoles and six, so-called MSE, conventional DC electromagnetic septum magnets. A protection element, so-called TPSG, has been placed immediately upstream of the first septum coil. The septum magnets and TPSG are mounted on a single mobile retractable support girder. The MSE septa are connected by a so-called plug-in system to a rigid water-cooled bus-bar, powered by water-cooled cables. The whole system is kept at the required vacuum pressure by ion pumps attached to separate pumping modules. In this note we present the design features and parameters of the MSE septum magnets, describe the function of the related main equipment elements, briefly report on the control and interlock requirements, and finally discuss the magnet cooling system.
\end{abstract}

Index Terms-Electromagnetic, extraction channel, septa, septum magnet, water-cooled copper coils.

\section{INTRODUCTION}

$\mathbf{F}$ OR the extraction of the beam from the SPS to the CNGS facility and ring 2 of the LHC a single turn fast extraction system will be used [1]. In this configuration, a horizontal closed orbit bump is introduced to bring the beam close to the extraction septum, as illustrated in Fig. 1. An extraction kicker magnet [2], [3] then moves horizontally the entire beam across the active septum element into the high field region of six MSE septum magnets which then deflect the beam $12.5 \mathrm{mrad}$ horizontally out of the SPS vacuum chamber and into transfer line TT40 [4], [5]. In case of a mis-steered beam, the MSE septum coils are protected by a TPSG diluter element placed immediately upstream of the first septum coil.

The MSE magnets are installed on a $23 \mathrm{~m}$ long support girder, which is motorized for the purpose of aperture optimization, and are connected by a 'plug-in' system to a fixed water-cooled bus-bar system powered by water-cooled cables. A cross-section of the system is shown in Fig. 2.

\section{MSE Electrostatic SEPTA}

At extraction the $\int \mathrm{Bdl}$ required for the $12.5 \mathrm{mrad}$ horizontally deflection is $18.9 \mathrm{Tm}$. To achieve this, the extraction channel LSS4 has been equipped with 6 conventional elec-

Manuscript received October 20, 2003.

The authors are with the European Organization for Nuclear Research, CERN, AB Division, BT Group, 1211 Geneva 23, Switzerland (e-mail wim.weterings@cern.ch).

Digital Object Identifier 10.1109/TASC.2004.829688

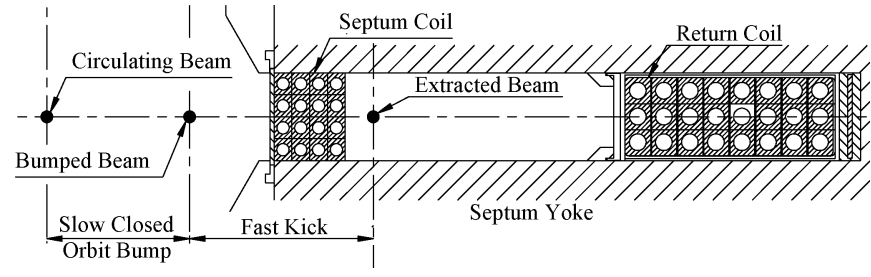

Fig. 1. Fast extraction process.

TABLE I

MSE SEPTUM MAGNET PARAMETERS

\begin{tabular}{lcc}
\hline \hline Septum Thickness & $\mathrm{mm}$ & 17.25 \\
Gap Height & $\mathrm{mm}$ & 20 \\
Maximum Field & $\mathrm{T}$ & 1.508 \\
Kick at $450 \mathrm{GeV} / \mathrm{c}$ & $\mathrm{mrad}$ & 2.249 \\
Magnetic Length & $\mathrm{m}$ & 2.237 \\
JB.dl max & $\mathrm{Tm}$ & 3.373 \\
Peak Current & $\mathrm{A}$ & 24,000 \\
JB.dl / I & $\mathrm{Tm} / \mathrm{A}$ & $1.410^{-4}$ \\
Total Resistance & $\mathrm{m} \Omega$ & 3.48 \\
Total Inductance & $\mu \mathrm{H}$ & 84 \\
Peak Voltage & $\mathrm{V}$ & 80 \\
Minimum rise/fall Time & $\mathrm{ms}$ & 200 \\
Magnet Spacing (centre) & $\mathrm{mm}$ & 3,234 \\
\hline \hline
\end{tabular}

TABLE II

MSE SEPTUM COIL PARAMETERS

\begin{tabular}{lccc}
\hline \hline & & Septum Coil & Return Coil \\
\hline Height & $\mathrm{mm}$ & 17.24 & 17.8 \\
Thickness & $\mathrm{mm}$ & 19.9 & 48 \\
Length & $\mathrm{mm}$ & 1105 & \\
Number of Conductors & & 16 & 24 \\
Size of Conductor & $\mathrm{mm}$ & $4.95 \times 4$ & $6 \times 6$ \\
Hole in Conductor & $\mathrm{mm}$ & $\varnothing 2.8$ & $\varnothing 3.8$ \\
Copper Septum Plate & $\mathrm{mm}$ & $22 \times 0.94$ & \\
Mean Copper Area & $\mathrm{mm}^{2}$ & 240 & 592 \\
Min. Coil Copper Area & $\mathrm{mm}^{2}$ & 213 & 196 \\
Insulation Thickness & $\mathrm{mm}^{-2}$ & & 1 \\
Peak Current Density & $\mathrm{A} \cdot \mathrm{mm}^{-2}$ & 112.8 & 122.2 \\
\hline \hline
\end{tabular}

tromagnetic septum magnets (MSE), which for reasons of standardization are identical to those used in extraction channels LSS2 and LSS6 of the SPS. The main parameters of the MSE magnets are given in Table I [6].

\section{A. Septum Coils}

Each magnet consists of a $2460 \mathrm{~mm}$ long single turn copper coil, formed by the septum- and return-coils, powered in series. The coils, of which the main parameters are given in Table II, are manufactured from cold drawn OFHC (Oxygen Free-High Conductivity) copper tubes [7]. The copper tubes are cleaned and locally annealed at $800^{\circ} \mathrm{C}$ followed by bending and machining 


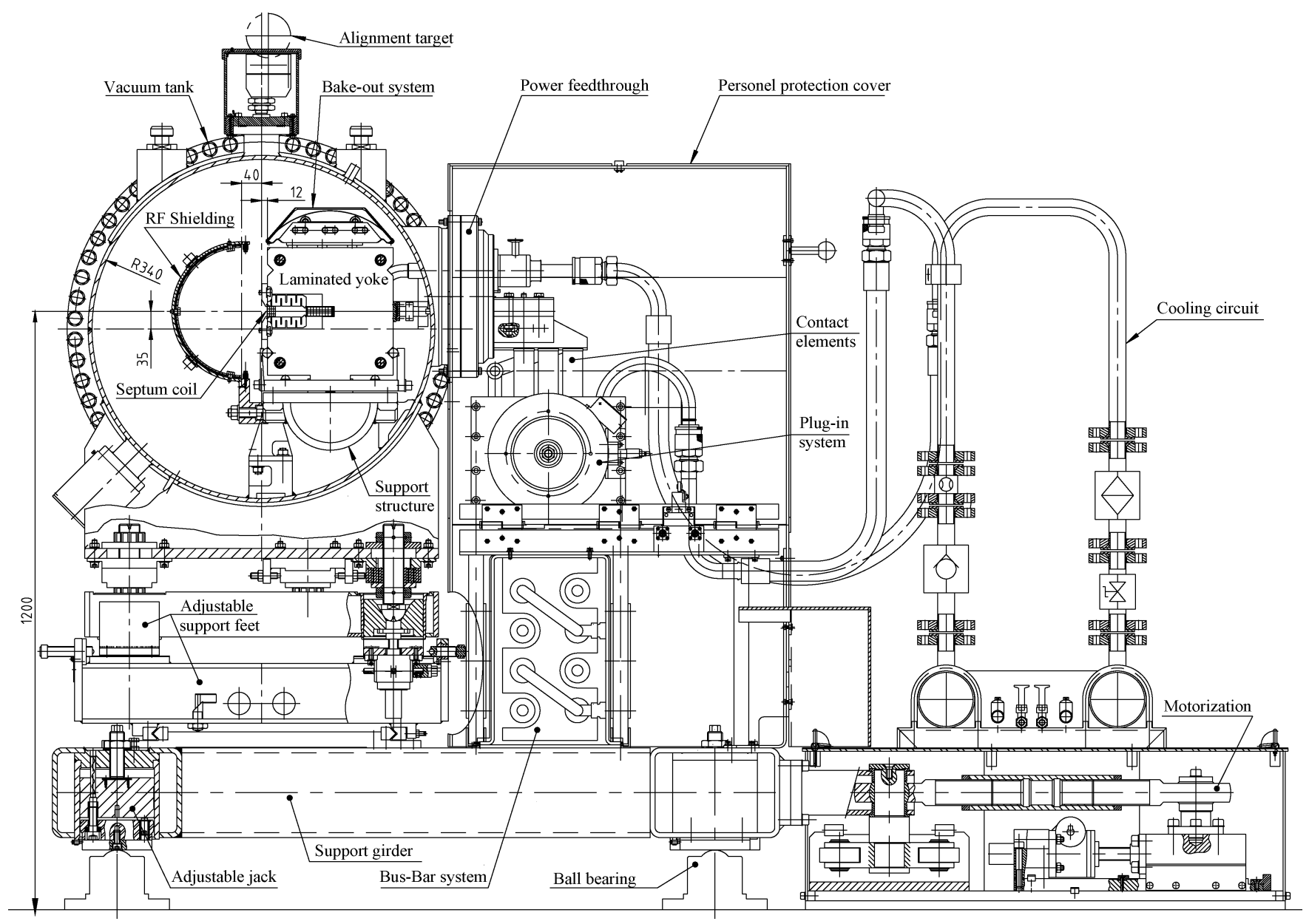

Fig. 2. Typical cross-section of the electromagnetic extraction septa installation (beam coming toward the reader).

to the required shape and dimension. Assembled in special purpose moulds the coils are vacuum brazed in several stages using braze with increasing melting points. After assembly, the coils are fitted tightly inside the $20 \mathrm{~mm}$ gap of two $1100 \mathrm{~mm}$ laminated yokes, the return coil being insulated by $4 \times 250 \mu \mathrm{m}$ layers of polymerized Polyimide insulation Pyralin.

\section{B. Laminated Yoke}

The yoke, of which the main parameters are given in Table III, consists of laminations blanked from $1.5 \mathrm{~mm}$ thick "steam-blued" Magnetil BC mild steel, oxidized in an air-circulation furnace at $340^{\circ} \mathrm{C}$ for 4 hours in order to ensure a good primary insulation [8]. During assembly, each pack of 25 laminations is separated by a Kapton layer for additional insulation and the yoke is assembled by means of 4 tie rods and insulation washers with a torque of $50 \mathrm{Nm}$. The total longitudinal electric resistance is then higher than $10 \mathrm{M} \Omega$.

\section{Support Structure}

Both yokes are supported inside the vacuum tank by use of stainless steel support structures, which comprise a $2456 \mathrm{~mm}$ large semi-circular cross-member on which left and right-hand base-plates are fitted on 6 hardened steel balls $\varnothing 16 \mathrm{~mm}$. By using special flanges and ceramic rods, the yoke is locked in position allowing an alignment to within $\pm 0.15 \mathrm{~mm}$ [9].

TABLE III

MAIN CHARACTERISTICS OF MSE LAMINATED YOKE

Mass of yoke

Nominal length

Straightness, surface planeness
Compression between laminations

Minimum Stacking factor

Area of a lamination

Maximum burr

Resistance of 10 laminations

Resistance of 1 yoke

Vacuum Bake-out temperature
Residual gas pressure

\begin{tabular}{cc}
$\mathrm{kg}$ & 520 (approx.) \\
$\mathrm{mm}$ & $1,100 \pm 0.5$ \\
$\mathrm{~mm}$ & 0.3 \\
$\mathrm{daN} / \mathrm{cm}$ & 5 \\
& 0.97 \\
$\mathrm{~m}^{2}$ & 0.05975 \\
$\mathrm{~mm}$ & 0.03 \\
$\Omega / \mathrm{cm}^{2}$ & $>0.033$ \\
$\mathrm{M} \Omega$ & $>10$ \\
${ }^{\circ} \mathrm{C}$ & 200 \\
$\mathrm{~Pa}$ & $10^{-7}$ \\
\hline
\end{tabular}

\section{Vacuum Tank}

Finally the whole assembly is mounted inside the special purpose vacuum tanks. These tanks form an integral part of the SPS vacuum system, inside which the residual pressure has to be around $10^{-7} \mathrm{~Pa}\left(10^{-9} \mathrm{mbar}\right)$ [10]. The power and water feedthrough of the coil is ensured by special purpose Ultra High Vacuum (UHV) flanges, equipped with a bellows insulator, consisting of ceramic $\left(\mathrm{Al}_{2} \mathrm{O}_{3}\right)$ insulators to which ends small $\mathrm{NiFeCo}$ collars are brazed. Two bellows with their end-pieces are welded onto each side of these insulators forming a vacuum barrier and allowing for movement due to thermal expansion of the coils. 
TABLE IV

Main Parameters of Cu-OF Tubes Used For the MSE Bus-BAR System

\begin{tabular}{lcc}
\hline \hline External diameter \& tolerances & $\mathrm{mm}$ & $49.5^{0 /-0.2}$ \\
Internal diameter \& tolerances & $\mathrm{mm}$ & $22^{ \pm 0.2}$ \\
Nominal cross section & $\mathrm{mm}^{2}$ & 1544 \\
Mass resistivity at $20^{\circ} \mathrm{C}$ & $\Omega \mathrm{g} / \mathrm{m}^{2}$ & $<0.15344$ \\
Volume resistivity at $20^{\circ} \mathrm{C}$ & $\mu \Omega \mathrm{m}$ & $<0.01724$ \\
Electrical conductivity & $\%$ & 100 IACS \\
$\mathrm{Cu}$ content & $\%$ & 99.95 \\
Oxygen content & $\mathrm{ppm}$ & $<10$ \\
\hline \hline
\end{tabular}

\section{Plug-IN SYSTEM}

At the outside of the magnet tank, high current contact elements are connected to the coils by aid of flat braided strands (tresses). These contact elements consist of $40 \mathrm{~mm}$ thick copper plates equipped with multi-contact strips and are pressed with an 870 daN force against the contact plates of the bus-bar system. This is done by a so-called plug-in system, as shown in Fig. 2, which allows rapid exchange of magnets in the generally radioactive environment [11]. The force on the contact plates is exercised by a stack of 40 spring-washers $(\varnothing 50 / \varnothing 25.4 \times$ $2.5 \mathrm{~mm}, \mathrm{~h}=1.4 \mathrm{~mm}, \mathrm{l}_{0}=3.9 \mathrm{~mm}$ ) and can be released by use of bellows assemblies with a working pressure of 4.5 bars [12]. The choice and design of all components has been made such that a reliable operation in the radioactive environment can be guaranteed.

\section{VACUUM PUMPING MODUleS}

Between each MSE septum, there is a vacuum pumping module (MP) equipped with two 400 Torr $\mathrm{l} \cdot \mathrm{s}^{-1}$ ionic vacuum pumps. The MP's are equipped with 'pirani-penning' gauges and the first and last MP's of the extraction equipment are also used to house the beam instrumentation systems. Without beam the system vacuum pressure will be about $2 \times 10^{-9} \mathrm{mbar}$, changing to about $8 \times 10^{-9}$ mbar due to outgassing once the power supply is switched on and the magnets are pulsing.

\section{BUS-BAR SYSTEM}

A $25 \mathrm{kA}$, water-cooled, copper bus-bar system is used to power all the magnets in series. The bus-bar consists of four in-series connected tubes with crossing return bars to minimize stray magnetic field during pulsing of the magnets.

The material used for the bus-bar system, Table IV, consists of straight high purity oxygen free $(\mathrm{Cu}-\mathrm{OF})$ copper tubes annealed after cold work with a minimum electrical conductivity of $100 \%$ IACS [13]. The copper was certified to be free of cracks, porosity and voids and very good characteristics for brazing were required. In order to ensure optimum electrical contact and avoid oxidation, all parts of the bus-bar have been brazed in a vacuum oven.

The bus-bar system is connected to the power supply by use of 10 water-cooled cables giving sufficient margin for the $I_{R M S}$ requirements of all possible SPS cycles, mentioned in Table V. The cooling requirements of the bus-bar system are given in Section VIII, Table VII.
TABLE $\mathrm{V}$

REQUIREMENTS FOR MSE POWER SUPPLY

\begin{tabular}{|c|c|c|}
\hline CNGS Cycle Length & $\mathrm{s}$ & 6 \\
\hline $\mathrm{LHC}_{\text {proton }}$ Cycle Length & $\mathrm{s}$ & 21.6 \\
\hline LHC lead Cycle Length & $\mathrm{s}$ & 49.2 \\
\hline Peak Current $\left(\mathrm{I}_{\max }\right)$ & A & 24,000 \\
\hline I RMS CNGS 400GeV & A & 7,950 \\
\hline $\mathrm{I}_{\mathrm{RMS}} \mathrm{CNGS} 450 \mathrm{GeV}$ & A & 8,944 \\
\hline $\mathrm{I}_{\mathrm{RMS}} \mathrm{CNGS} 350 \mathrm{GeV}$ & A & 6,957 \\
\hline $\mathrm{I}_{\mathrm{RMS} S} \mathrm{LHC}_{\text {proton }} 450 \mathrm{GeV}$ & A & 4,714 \\
\hline $\mathrm{I}_{\mathrm{RMS}} \mathrm{LHC}_{\text {lead }} 450 \mathrm{GeV}$ & A & 3,123 \\
\hline Max. RMS Current (I & A & 10,000 \\
\hline$\sum$ RMS Power dissipation & $\mathrm{kW}$ & 348 \\
\hline Total Peak Power & $\mathrm{kW}$ & 2,099 \\
\hline
\end{tabular}

TABLE VI

Boundary VALUeS AND Result of CALCULATIONS ON HoRIZONTAL DEFLECTION DUE TO GIRDER MOVEMENT

\begin{tabular}{lcc}
\hline \hline Girder Length & $\mathrm{mm}$ & 23,012 \\
Position Upstream Motor & $\mathrm{mm}$ & 6,020 \\
Position Downstream Motor & $\mathrm{mm}$ & 18,956 \\
Weight / Girder Section & $\mathrm{kg}$ & 5,000 \\
Rolling Coefficient Ball Bearings & $\%$ & 1 \\
Friction Force / Bearing & $\mathrm{N}$ & 250 \\
Assumed Bellows Force & $\mathrm{N}$ & 1,000 \\
Resistance Water-cooled Cables & $\mathrm{N}$ & 1,000 \\
Required Force Upstream Motor & $\mathrm{N}$ & 5,025 \\
Required Force Downstream Motor & $\mathrm{N}$ & 5,875 \\
Maximum Deflection Upstream End & $\mathrm{mm}$ & 0.05 \\
Maximum Deflection Downstream End & $\mathrm{mm}$ & 0.04 \\
Maximum Deflection Centre & $\mathrm{mm}$ & 0.01 \\
\hline \hline
\end{tabular}

\section{MOTORIZED SUPPORT GIRDER}

The magnets, MP's and TPSG are mounted on a $23 \mathrm{~m}$ long support girder using adjustable support feet, allowing horizontal and vertical alignment. The girder is assembled from seven elements, typically $3.3 \mathrm{~m}$ long and consisting of a welded structure made of $260 \times 180 \times 10 \mathrm{MSH}$ type profiles [14], connected together by intermediate joining plates. To allow vertical alignment, each element is equipped with 4 adjustable jacks, which themselves stand on ball bearings.

The girder has been motorized in order to optimize the local SPS aperture during setting up. The girder movement is achieved with a precision and reproducibility of $\pm 0.1 \mathrm{~mm}$ using two independent motors. The magnets on the girder are pre-aligned to follow the trajectory of the extracted beam to maximize the aperture [15], [16]. The longitudinal position of the two motors was confirmed by ANSYS calculations to exercise minimum flexion of the girder, which occurs due to friction of the ball bearings, mechanical resistance of the water-cooled cables and tension of the vacuum bellows at both ends. Table VI shows the boundary values and calculation results. Position measurement devices are installed near the extremities of the girder for reasons of accessibility and to increase the measurement precision.

\section{BEAM INSTRUMENTATION}

Each MSE magnet is equipped with a Beam Loss Monitor (BLM) and the measurements of the beam losses can be used for correcting the beam trajectories in order to keep the irradiation level of the accelerator components at the lowest pos- 
TABLE VII

MAIN PARAMETERS OF MSE COOLING REQUIREMENTS

\begin{tabular}{lcc}
\hline \hline Inlet Water Temperature & ${ }^{\circ} \mathrm{C}$ & 18 \\
Outlet Water Temperature & ${ }^{\circ} \mathrm{C}$ & 27.8 \\
Pressure Drop Magnet & Bars & 10.23 \\
Pressure Drop Bus-Bars+Cables & Bars & 1.88 \\
Min. Flow Rate Magnet & $1 \cdot \mathrm{s}^{-1}$ & 1.0 \\
Flow Rate Bus-Bars+Cables & $1 \cdot \mathrm{s}^{-1}$ & 2.1 \\
Total Flow Rate & $1 \cdot \mathrm{s}^{-1}$ & 8.2 \\
$\Delta$ T water magnet at (IRMs) & ${ }^{\circ} \mathrm{C}$ & 8 \\
$\Delta$ T water Bus-Bars (IRMS) & ${ }^{\circ} \mathrm{C}$ & 1.1 \\
$\Delta$ T water cables (IRMS) & ${ }^{\circ} \mathrm{C}$ & 15 \\
Nom. Water Speed in Septum & $\mathrm{m} \cdot \mathrm{s}^{-1}$ & 6.3 \\
Water Speed in Bus-Bars & $\mathrm{m} \cdot \mathrm{s}^{-1}$ & 0.68 \\
Water Speed in Cables & $\mathrm{m} \cdot \mathrm{s}^{-1}$ & 1.33 \\
$\Delta$ T Septum Coil (copper) & ${ }^{\circ} \mathrm{C}$ & 10.4 \\
$\Delta$ T Return Coil (copper) & ${ }^{\circ} \mathrm{C}$ & 16.0 \\
\hline \hline
\end{tabular}

sible level. Furthermore, to control the extracted beam, Beam Position Monitors (BPM) are placed directly upstream of the extraction equipment, in front of the TPSG diluter and downstream after the last MSE magnet.

\section{COOLING}

In order to evacuate the dissipated power during pulsing of the magnets $(\sim 350 \mathrm{~kW})$ and to maintain the septa at $\sim 20^{\circ} \mathrm{C}$, a special purpose cooling system has been installed. This cooling system constitutes of a primary circuit of chilled water $\left(\sim 13^{\circ} \mathrm{C}\right)$ passing through a heat exchanger cooling the secondary circuit which is powered by a $50 \mathrm{~m}^{3} \cdot \mathrm{h}^{-1}$ pump. The de-mineralized water of the secondary circuit is filtered by a $10 \mu \mathrm{m}$ filter and isolated from the MSE septa cooling circuit by special purpose valves.

The MSE cooling circuit has been equipped with a by-pass valve in order to fill the entire circuit and circulate water without passing through the septa coils, this in order to ensure that all trapped air and contaminations, which could damage the coils, are filtered out. Each MSE magnet is independently connected to this circuit and is equipped with a valve to isolate the magnet from the circuit, a $20 \mu \mathrm{m}$ filter in order to avoid residual particles to enter into the septum, a water temperature gauge, a flow meter and a nonreturn valve.

Table VII shows the main parameters of the MSE cooling system which are controlled and regulated by the MSE control system as described in chapter [2].

\section{CONTROLS}

In order to protect the system, a multitude of measurements, such as water-flow, pressure, temperature, vacuum limits, water resistance, plug-in closure, personnel security, etc. are checked against a defined set of parameters by a PLC operated control system. This system regulates the required values and manages an interlock with the power supply in case of failure of the equipment or functioning above the predefined set of limits. This system also controls the girder position and motorization settings and regulates the power supply for compensation.

The PLC controller can be accessed remotely for data acquisition, changing of parameter settings or modification of the interlock status and an alarm system is incorporated which directly informs the control room of any abnormal situation.

\section{CONCLUSION}

A 23 meter long rigid and retractable support girder equipped with six MSE septum magnets, six pumping modules and a TPSG diluter with associated instrumentation, control, powering and cooling equipment has successfully been installed, commissioned and tested in the long straight section LSS4 of the SPS.

On 8 and 9 September 2003 the new beam extraction system and the subsequent downstream transfer line TT40 were commissioned and tested for the first time with beam when single "LHC pilot bunches" were extracted from the SPS.

\section{ACKNOWLEDGMENT}

The authors wish to thank the members of the former SL-BT-EX section, the former SL-BT-EC section and the other teams responsible for the supply and installation of components for their motivation, constant support and excellent work in achieving the manufacture, assembly and installation of all the equipment involved within the limits of the timeframe and budget as planned.

\section{REFERENCES}

[1] P. Collier et al., "The SPS as injector for LHC: conceptual design,", CERN SL 97-07 (DI), 1997.

[2] J. Uythoven, "The MKE Home Page," [Online] http://uythoven.home. cern.ch/uythoven/Html/MKE/MKE_home.htm, accessed August 2003.

[3] E. Gaxiola, J. Uythoven, and M. Timmins, Upgrade of the SPS extraction kickers for LHC and CNGS operation, CERN SL 2002-042 (BT), 2002.

[4] A. Hilaire, V. Mertens, and E. Weisse, "Beam transfer to and injection into LHC,", CERN-LHC-Project-Report-208, 1998.

[5] B. Goddard et al., "The new extraction channel for LHC and CNGS,", CERN SL 2000-036 (BT), 2000

[6] J. Dupin, "Extraction septum magnets for the SPS—list of parameters,", CERN/SPS/ABT/EX/JD/ph/81-42, 1981.

[7] W. Weterings et al., "Fabrication de tubes de haute précision en cuivre,", CERN SL 2000-26 BT, 2000.

[8] A. Rizzo, "Manufacture of septum electromagnet yokes for the SPS accelerator,", CERN SL 98-33 MS, 1998, revised W. Weterings, 2000.

[9] W. Weterings, "Supply of stainless steel support structures,", CERN SL 2002-02 BT, 2002.

[10] R Guinand, "Large ultra-high vacuum tanks for SPS extraction septa,", CERN IT-2869/SL2001, revised R. Guinand, 2002.

[11] W. Weterings, "Supply of MSE plug-in systems,", CERN SL 2000-034 BT, , 2000

[12] M. Goujon, "Note de calcul plug-in,", CERN LAB II/ME-DO/G MA, 1974.

[13] W. Weterings, "Supply of Copper Tubes,", CERN SL 2000-21 BT, 2000.

[14] — , "The supply of a welded mobile support girder for MSE septum magnets,", CERN SL 2000-25 BT, 2000.

[15] W. Scandale, "Alignement des septa," Tech. Note/75-6, CERN LABII/BT/WS/JK/E, 1975, revised R. Guinand, 1976.

[16] B. Balhan et al., "Alignment and girder position of MSE septa in the new LSS4 extraction channel of the SPS,", CERN SL 2002-014 BT, 2002. 